\title{
Crenças Indicativas de Resiliência Parental no Contexto do Autismo
}

\author{
Marcia Rejane Semensato ${ }^{1}$ \\ Cleonice Alves Bosa \\ Universidade Federal do Rio Grande do Sul
}

\begin{abstract}
RESUMO - A resiliência parental refere-se a uma parentalidade sensível e cuidadosa diante de situações críticas, como em processos diagnósticos de autismo envolvendo os filhos. Trata-se de um processo que permite aos pais desenvolver uma relação protetora frente às necessidades dos filhos e às do próprio casal, bem como elaborar o diagnóstico recebido. No atual estudo, investigaram-se indicativos de resiliência parental através da análise de conteúdo de seis entrevistas com casais cujo filho apresenta autismo. Os resultados revelaram que (a) a busca e a atribuição de sentido ao comportamento do filho e ao próprio termo autismo e (b) a capacidade de desenvolver um empoderamento nessa vivência, foram indicativos de resiliência parental importantes no processo de elaboração do diagnóstico de autismo do filho.
\end{abstract}

Palavras-chave: autismo,pais, casal, resiliência,diagnóstico

\section{Beliefs Indicating Parental Resilience in the Context of Autism}

\begin{abstract}
Parental resilience refers to a sensitive and careful parenting in critical situations, such as in diagnostic processes of autism involving children. Parental resilience allows parents to develop a protective relationship that takes the needs of the child and the couple into consideration, and to assimilate the received diagnosis. In the current study the indicatives of parental resilience were investigated through Content Analysis of six interviews with couples having a child with autism. The results showed that (a) the search and attribution of meaning to the characteristics of their child and to the term autism and (b) the capacity to develop an empowerment of their experience were important indicatives of parental resilience involved in the process of assimilation of the autism diagnosis of their child.
\end{abstract}

Keywords: autism, parents, couple, resilience, diagnosis

O constructo resiliência, na psicologia positiva (Ruini \& Fava, 2013), pode ser compreendido como uma metáfora que expressa a capacidade das pessoas para superar, com relativo sucesso, condições adversas ou situações que envolvam risco ao seu bem-estar, desenvolvimento e saúde mental (Amar, Gonzales, \& Utria, 2013; Reppold, Mayer, Almeida, \& Hutz, 2012). Essa capacidade não significa resistência absoluta ao estresse e também não se resume a traços individuais, mas engloba trajetórias de desenvolvimento, de superação para lidar com eventos estressores, nas quais as pessoas, além de suas características individuais, contam, por exemplo, com o apoio de sua rede social e afetiva (Paula Júnior \& Zanini, 2011; Poletto, 2008).

Na perspectiva da psicologia do desenvolvimento, diversos estudos nessa temática investigam indivíduos em situação de vulnerabilidade social e baseiam-se na teoria bioecológica do desenvolvimento humano (Yunes \& Juliano, 2010; Koller, Dell'Aglio, \& Yunes, 2006). Contudo, na psicologia clínica, uma parcela das discussões sobre a resiliência ocorre na área da teoria sistêmica com foco nos processos familiares.

1 Endereço para correspondência: Rua Ramiro Barcelos, 2600, Sala 110, Porto Alegre, RS, Brasil. CEP: 90.035-003.E-mail: msemensato@ gmail.com

\section{Resiliência Familiar com Foco no Casal Parental}

O estudo da resiliência nas famílias está baseado na convicção de que todas as famílias possuem potenciais para o crescimento (Rooke \& Pereira-Silva, 2012). Para Walsh (2012), o processo da resiliência familiar é descrito por meio de um sistema de crenças construído pela família acerca dos (a) Padrões de Organização Familiar, ou seja, flexibilidade e coesão das relações, recursos sociais e econômicos da família, e (b) Processo de Comunicação da Família, responsável pela transmissão das crenças, pela expressão emocional e pela forma de resolução de problemas na família, entre outros fatores. Não se trata, no entanto, de uma tipologia de traços de famílias resilientes, mas de processos dinâmicos envolvendo forças e recursos que as famílias podem desenvolver (Walsh, 2012). Esses processos, de acordo com a autora, também são atuantes nos subsistemas, ou seja, o processo de resiliência também pode ser compreendido, por exemplo, no casal parental. O conceito de resiliência parental, de acordo com López (2009), refere-se a uma parentalidade sensível e cuidadosa nas situações críticas; um processo dinâmico que permite aos pais desenvolver uma relação protetora frente às necessidades dos filhos. No presente artigo, será enfocada a resiliência parental através do sistema de crenças dos pais tendo como base o modelo proposto por Walsh,que trabalha extensivamente $\mathrm{o}$ aspecto das crenças. 


\section{Resiliência: O Sistema de Crenças}

As crenças individuais, de casal ou familiares vêm sendo reconhecidas como influências importantes na compreensão das pessoas acerca dos acontecimentos e eventos do mundo. Essas crenças, como afirmou Pinker (2004), são teorias que todos têm sobre a natureza humana; e essas teorias estão implícitas nas decisões que são tomadas e que direcionam, entre outras coisas, a maneira de criar os filhos, os objetivos e valores parentais. Em consonância com esse posicionamento, Biasoli-Alves (2000) afirma que os valores e crenças compartilhados pelos pais sobre o desenvolvimento do filho influenciam o comportamento e as práticas parentais, além de afetar as interações que são estabelecidas com as crianças.

No modelo sistêmico de Walsh (2012), o sistema de crenças é definido como os valores, convicções, atitudes, etc., que influenciam as respostas emocionais, decisões e ações das pessoas na família. Por esse motivo é considerado um aspecto chave na resiliência. As crenças proveem coerência e organizam a experiência, permitindo aos membros da família fazer sentido de suas situações de crise. Elas envolvem a capacidade de esperança, perseverança, foco nos potenciais, crenças espirituais transcendentes, etc. Além disso, o significado atribuído ao estressor, a avaliação subjetiva da família acerca deste e a habilidade para lidar com ele - o empoderamento $^{1}$ - são aspectos importantes na resiliência (Patterson, 2002; Walsh, 2012).

Uma das situações que tende a ser mais crítica pelos desafios que impõe aos pais é a que se refere a dificuldades no desenvolvimento dos filhos, seja por alguma condição orgânica ou mental. Entre elas, destaca-se o transtorno do espectro do autismo (TEA).

\section{Resiliência no Contexto dos TEA}

O DSM - V (American Psychiatric Association, 2013) aponta como critérios diagnósticos para o Transtorno do Espectro do Autismo (TEA) a presença de comprometimento nas interações sociais recíprocas e nas modalidades de comunicação, bem como interesses e atividades restritos, estereotipados e repetitivos. A gravidade e cronicidade desses comprometimentos tornam o TEA um estressor potencial para os pais (Milshtein, Yirmiya, Oppenheim, Koren-Karie,\& Levi, 2010; Schmidt \& Bosa, 2007; Meimes, 2014; Walsh \& O’Leary, 2013). Por outro lado, há evidências de que o impacto do autismo na família parece estar relacionado não somente a esses aspectos, mas também a crenças familiares sobre o autismo e sobre o desenvolvimento do filho, bem como à rede de apoio conjugal e social (Meimes, 2014; Semensato, Schmidt, \& Bosa, 2010; Sifuentes \& Bosa, 2010). Além disso, esse impacto pode variar e tende a ser vivenciado como um luto, ocorrendo sentimentos de tristeza e raiva, ou mesmo depressão e, ainda, conflitos entre os cônjuges (Fleischmann, 2004; Milshtein, et al., 2010). Por outro lado, pode haver também um senso de alívio, de aumento

1 Processo pelo qual as famílias acessam habilidades e recursos, o que facilita um senso de controle em suas vidas, com efeito na qualidade de vida (Singh, 1995). da proximidade e de solidificação da relação (Hutton \& Caron, 2005; Semensato \& Bosa, 2014). Nesse sentido, os pais costumam descrever essa vivência como um longo processo de aprendizagem para lidar com os desafios impostos pelo autismo e criar as condições essenciais para a reestruturação das suas vidas.

Há evidências de que as crenças parentais acerca do autismo têm influência na forma como esse diagnóstico impacta o casal de pais e nas escolhas terapêuticas que fazem para a criança (Dardennes et al., 2011; Harrington, Patrick, Edwards, \& Brand, 2006; Herbert \& Koulouglioti, 2010). Portanto, as crenças dos pais podem funcionar como um aspecto tanto de proteção quanto de vulnerabilidade ao lidar com o diagnóstico de autismo que acomete o filho. De fato, as pesquisas em resiliência familiar focam exatamente os aspectos de proteção e de crescimento familiar em face de riscos específicos ou, mais especificamente, visam à possiblidade de promoção desses fatores (Walsh, 2012). No caso do autismo, isso é essencial no planejamento de intervenções com as famílias e crianças, tendo em vista que essa condição tende a acompanhar a família durante o ciclo vital, requerendo uma série de mudanças.

O subsistema do casal de pais tem importantes reflexos no sistema familiar, no que se refere ao cuidado e bem-estar dos filhos. Isso se dá através dos aspectos relacionais da resiliência, ou seja, da qualidade da parentalidade e da coparentalidade (Hartling, 2008). Em termos conceituais, a coparentalidade é uma área de estudos mais delimitada da parentalidade e surgiu no bojo das investigações envolvendo o divórcio e o cuidado dos filhos. Esse conceito se refere especificamente ao quanto os casais trabalham conjuntamente na criação dos filhos, apoiam-se mutuamente nessa tarefa e negociam diferenças, independente de viverem juntos (Sifuentes \& Bosa, 2010). A investigação desses dois processos, a parentalidade e a coparentalidade, ao focar a dinâmica relacional em situações adversas, pode então fornecer importantes indicativos de resiliência parental.

$\mathrm{O}$ aspecto relacional da resiliência refere-se à dinâmica interacional dos pais frente a situações de adversidade, no que tange ao apoio emocional, a um compartilhamento de lógicas no diálogo do casal e à construção de significados compartilhados acerca da vida, ou de acontecimentos que tendem a ser adversos para a família (Hartling, 2008; Melillo \& Ojeda, 2005). Outros autores ainda enfatizam como aspectos relacionais da resiliência o aumento do laço relacional e da aceitação mútua, bem como respeito, valores compartilhados e maior confiança um no outro para pedir auxílio (Connolly, 2006; Lamana \& Riedman, 2009).

Especificamente no contexto do autismo, o estudo de Gardner e Harmon (2002) investigou a resiliência parental por meio de entrevistas com seis mães de crianças com TEA. A análise qualitativa fenomenológica das entrevistas indicou que a resiliência dos pais estava relacionada a uma atitude positiva frente à vida, à capacidade de organização e confiança, ao reconhecimento de suas forças e limitações, à existência de parceiros apoiadores e ao forte senso de sentido na vida, como, por exemplo, crenças religiosas. No entanto, apesar de visar à investigação da resiliência 
parental, esse estudo se limitou a entrevistar as mães e não o casal de pais.

Em se tratando de resiliência parental, é importante compreender como alguns casais lidam com as situações de adversidade e ainda conquistam, além de um crescimento pessoal, um desenvolvimento no casal, como, por exemplo, consolidação do relacionamento, desenvolvimento da empatia na relação, valorização da conexão, etc. (Hartling, 2008) com reflexos na relação familiar. A capacidade do casal para trabalhar junto e se apoiar mutuamente parece ser um facilitador tanto para o cuidado e desenvolvimento do filho com autismo, quanto no cuidado familiar e na reorganização necessária nesse momento. No âmbito da clínica psicológica, é comum empregar-se o termo elaboração do diagnóstico para se referir a esse processo. Contudo, o termo é praticamente utilizado como "jargão", carecendo de um adensamento teórico. Partindo dessas premissas, este estudo tem como objetivo principal investigar, respectivamente, os indicativos de resiliência em casais que são pais de crianças com autismo durante os primeiros anos após o diagnóstico do filho. Como objetivo secundário, pretende-se buscar subsídios no conceito de resiliência para a melhor compreensão do que se denomina, na clínica psicológica, de elaboração do diagnóstico do filho.

\section{Método}

\section{Delineamento e Participantes}

Este estudo utilizou um banco de dados com entrevistas de seis casais ${ }^{2}$ que possuem um filho com diagnóstico de autismo entre cinco e dez anos, que haviam participado de um estudo sobre coparentalidade e conjugalidade ${ }^{3}$. O diagnóstico do filho havia sido realizado há pelo menos dois anos na época da entrevista com os pais. Essas crianças, todas do sexo masculino, não apresentavam deficiência física ou sensorial associada ao autismo. Os casais eram coabitantes há pelo menos 11 anos, tinham idades entre 32 e 49 anos e dois ou mais filhos da atual união. Ambos os cônjuges eram os pais biológicos da criança com autismo.

\section{Procedimentos}

Entrou-se em contato com instituições que atendem a pessoas com autismo. Após a concordância da instituição, os pais foram convidados por telefone a participar do estudo. Foram realizadas entrevistas conjuntas com ambos os membros do casal na sua residência. Antes das entrevistas, houve a explicação do estudo, bem como a leitura e assinatura do Termo de Consentimento Livre e Esclarecido. As entrevistas duraram entre 90 e 120 minutos.

2 Os nomes dos participantes foram modificados.

3 Projeto aprovado no Comitê de Ética em Pesquisa da Universidade Federal do Rio Grande do Sul (processo número 2060030483).

\section{Materiais e Instrumentos}

1. Ficha de dados demográficos da família;

2. Roteiro para Entrevistas sobre coparentalidade e conjugalidade (Núcleo Integrado de Estudos e Pesquisa em Transtornos do Desenvolvimento [NIEPED], 2004): investigou tópicos tais como história familiar, relação com a família de origem, características individuais e do casal, conjugalidade, experiência coparental e parental desde o momento do processo diagnóstico até os dias atuais. A análise dos indicativos de resiliência foi realizada da seguinte maneira: as entrevistas foram analisadas com base na análise de conteúdo interpretativa (Minayo, 2006) das crenças dos casais de pais sobre Autismo, Filho e Casal, utilizando a definição de crenças, proposta por Walsh (2012). Por fim, construiu-se uma matriz de categorias de resiliência parental no contexto do autismo (Tabela 1), baseada em três temas principais (Autismo, Filho e Casal). No tema Autismo, foram geradas três categorias a priori: Processo Diagnóstico, Tratamentos e Impacto Familiar do Diagnóstico. O tema Filho gerou duas categorias: Características do Filho e Expectativas Futuras. O tema Casal gerou três categorias: Vivência da Coparentalidade, Vivência da Conjugalidade e Recursos Sociais e Econômicos. A apresentação tem como base uma subdivisão conforme as crenças que representavam um Senso de Amparo (SA) ou Senso de Desamparo (SD) nas diferentes categorias, por esses aspectos terem sido fundamentais na identificação dos indicadores de resiliência como a organização e a comunicação familiar.

\section{Resultados e Discussão}

Em termos dos indicativos estudados, no tema Autismo, a categoria de Processo Diagnóstico buscou compreender que vivências despertavam um senso de amparo ou de desamparo nos pais no período que eles caracterizaram como o período da busca do diagnóstico. Na categoria Processo Diagnóstico, oSenso de Amparo dos pais foi relacionado ao conhecimento dos profissionais sobre o desenvolvimento típico e atípico, o que facilita a identificação e consequentemente a intervenção precoce do autismo. Já o Senso de Desamparo em relação aos profissionais no Processo Diagnóstico foi ligado à crença de pais de que suas preocupações iniciais não eram levadas a sério, principalmente pelos pediatras, os primeiros procurados pelas famílias quando percebiam algo diferente com o filho: "a gente começou a procurar atendimento, só que era muito difícil, né, muito, muito difícil, porque ninguém dizia nada pra gente e as pessoas pareciam assim que... até fazia às vezes pouco caso"[M2]. O Senso de Desamparo também foi representado por crenças de que os profissionais têm pouco conhecimento sobre autismo e de que o conhecimento atual não responde a muitas dúvidas sobre o desenvolvimento da criança com autismo, a existência de poucos serviços especializados e a informações pouco acessíveis, conforme ilustra o relato a seguir: "Não sabia os 
sintomas, o que que ele podia fazer, o que não podia fazer. Daí quando eu li num dicionário,... explicava assim como um médico explica pra ti... daí tu não entende muito"[P4]. A experiência com os profissionais e com os sistemas de serviço no diagnóstico e na comunicação deste à família foi investigada também por Fleischmann (2004), Hutton e Caron (2005) e Osborne e Reed (2008). Fleischmann, por exemplo, analisou qualitativamente relatos de 20 narrativas de familiares que publicaram na internet sua experiência logo após o recebimento do diagnóstico de autismo. Os pais descreveram a comunicação do diagnóstico como uma experiência de desafio que mudou suas vidas. Os sentimentos descritos incluíam alívio, choque, culpa ou raiva. Já no estudo de Hutton e Caron (2005), entrevistas com 21 famílias acerca do impacto do diagnóstico de autismo revelaram, além de um senso de alívio, sentimentos de esperança, de perda e luto, bem como surpresa e autoculpabilização.

O conhecimento dos profissionais sobre o autismo foi tema de uma pesquisa com estudantes de Medicina de uma universidade do Rio Grande do Sul (Muller, 2012). Os dados indicaram um baixo conhecimento dos alunos sobre os comprometimentos característicos do autismo, tanto em alunos dos anos iniciais, quanto em alunos de anos finais do curso. Estudos internacionais também revelaram déficits nos conhecimentos dos profissionais envolvidos no diagnóstico e em intervenções com crianças com autismo na área da

Tabela 1. Matriz de categorias e subcategorias das crenças indicativas de resiliência parental no contexto dos TEA

\begin{tabular}{|c|c|c|}
\hline \multicolumn{3}{|l|}{ AUTISMO } \\
\hline \multirow[t]{2}{*}{$\begin{array}{l}\text { Processo } \\
\text { Diagnóstico }\end{array}$} & Senso de Amparo & $\begin{array}{l}\text {-Profissionais: conhecimento sobre autismo; habilidade na relação com famílias; } \\
\text {-Processo diagnóstico longo - início do tratamento; }\end{array}$ \\
\hline & Senso de Desamparo & $\begin{array}{l}\text {-Preconceito dos profissionais acerca da família ou da criança; } \\
\text {-Processo diagnóstico demorado; } \\
\text {-Muitos profissionais e exames envolvidos; }\end{array}$ \\
\hline \multirow[t]{2}{*}{ Tratamentos } & Senso de Amparo & $\begin{array}{l}\text {-Bom trato com a criança e com a família; } \\
\text {-Capacidade do profissional de trabalhar em equipe; } \\
\text {-Atendimento integrado em um local. } \\
\text {-Que o filho goste da pessoa do profissional }\end{array}$ \\
\hline & Senso de Desamparo & $\begin{array}{l}\text {-Falta de disponibilidade dos profissionais; } \\
\text {-Falta de habilidade dos profissionais; } \\
\text {-Poucas vagas no setor público; }\end{array}$ \\
\hline \multirow[t]{2}{*}{$\begin{array}{l}\text { Impacto Familiar do } \\
\text { Diagnóstico }\end{array}$} & Senso de Amparo & $\begin{array}{l}\text {-Conversas claras; empatia entre parceiros; } \\
\text {-Auxílio de amigos }\end{array}$ \\
\hline & Senso de Desamparo & $\begin{array}{l}\text {-Afastamento dos demais filhos; } \\
\text {-Desinvestimento do filho com autismo; } \\
\text {-Reações de negação do diagnóstico; desânimo, medos sobre o desenvolvimento e } \\
\text { futuro do filho; } \\
\text {-Diminuição da empatia entre os parceiros; afastamento; } \\
\text {-Reação de isolamento nas relações sociais; } \\
\text {-Preconceito dos conhecidos e amigos; }\end{array}$ \\
\hline \multicolumn{3}{|l|}{ FILHO } \\
\hline \multirow[t]{2}{*}{ Características } & Senso de Amparo & Potencialidades Afetivas, sentimentais; cognitivas; comunicação; \\
\hline & Senso de Desamparo & Comprometimentos Comportamentais, na comunicação e cognitivos; \\
\hline Expectativas futuras & Senso de Amparo & (In)dependência, desenvolver linguagem, aprender rotinas, inclusão; \\
\hline \multicolumn{3}{|l|}{ CASAL } \\
\hline \multirow[t]{2}{*}{ Coparentalidade } & Senso de Amparo & $\begin{array}{l}\text {-Esperança dos parceiros: ex. encontrar sentido no ter um filho com autismo; } \\
\text {-Comunicação do casal: ex. tomada de decisão compartilhada; }\end{array}$ \\
\hline & Senso deDesamparo & $\begin{array}{l}\text {-Desesperança: ex. falta de sentido do autismo, culpas foco nos comprometimentos do } \\
\text { parceiro e do filho; } \\
\text {-Comunicação: ex. expressão hostil dos sentimentos; } \\
\text {-Dificuldades na coesão, na flexibilidade, antagonismo; }\end{array}$ \\
\hline \multirow[t]{2}{*}{ ConjugaLidade } & Senso de Amparo & $\begin{array}{l}\text {-Esperança: ex. resgate da vida conjugal; } \\
\text {-Comunicação: expressão de sentimento; }\end{array}$ \\
\hline & Senso de Desamparo & $\begin{array}{l}\text {-Desesperança: ex. estranheza frente à vida conjugal; } \\
\text {-Comunicação do casal: ex. expressão de sentimentos de forma hostil; }\end{array}$ \\
\hline $\begin{array}{l}\text { Recursos Sociais e } \\
\text { Econômicos }\end{array}$ & Senso de Amparo & $\begin{array}{l}\text {-Equilíbrio entre trabalho e exigências familiares; } \\
\text {-Rede de Apoio: família extensiva, mobilização de apoio formal profissional, outros } \\
\text { pais de crianças com autismo, escola; } \\
\text {-Mobilização de outros recursos: busca de informação: busca de direitos legais; }\end{array}$ \\
\hline
\end{tabular}


Medicina, assim como também na área da Educação e da Psicologia (Heidgerken, Geffken, Modi, \& Frakey, 2005; Scheuermann, Webber, Boutot, \& Goodwin, 2003). Os dados refletem, portanto, uma falta de preparo acadêmico dos profissionais não somente no contexto brasileiro. De fato, a falha de preparo e de conhecimento dos profissionais é coerente com as queixas parentais, o que gera, ou eleva, o senso de desamparo destes. Por outro lado, parece haver indícios de melhora na formação: um levantamento realizado por Barnhill, Polloway e Sumutka (2011) com a participação de 87 instituições de educação superior nos Estados Unidos concluiu que, apesar de 41\% das instituições participantes ainda não oferecerem cursos específicos para TEA na graduação, houve um aumento na implementação de programas de preparação para lidar com pessoas com autismo. A natureza desses programas, no entanto, ainda mostrava uma grande variabilidade, como, por exemplo, nos tópicos abordados e no preparo para a prática profissional.

Outro aspecto, a duração longa do processo diagnóstico, foi compreendido como amparo por representar o "começo de uma reestruturação da família" [C2] e o início do tratamento do filho. O tempo foi importante para a elaboração do diagnóstico pelos familiares: "a gente sabia que alguma coisa era... só não sabia o que que era né” [P2];"mas naquele meio tempo ali, já tinha assim, ah, ele tem característica, ah, ele é assim, mas a gente não pode afirmar, então a gente já foi se acostumando com a ideia, a gente já foi procurando saber o que que era, sabe, a gente já foi conversando, mexeu com a familia" [M2].

Os relatos parentais indicam que, se o processo diagnóstico envolve mais do que uma informação final sobre "ter ou não ter autismo", ele é considerado como favorável ao bem-estar do casal e da família. Nesse caso, os pais relataram um Senso de Amparo facilitado quando, dentro da avaliação, o período da comunicação do diagnóstico foi realizado como um processo, no qual eles puderam falar sobre as suas ideias, conclusões, dúvidas, bem como seus sentimentos, expectativas e possibilidades de escolha. Isso, de fato, sugere que a comunicação desse diagnóstico também seja compreendida como um processo, em contraste com uma entrevista de informação do diagnóstico. A devolução da avaliação quando feita nesse processo parece permitir uma elaboração inicial do diagnóstico por parte dos pais. $\mathrm{Na}$ literatura sobre o tema, várias pesquisas sugerem que alguns pais sentem alívio no momento da comunicação do diagnóstico (Fleischmann, 2004; Hutton \& Caron, 2005; Milshtein et al., 2010), tendo em vista que percebiam que havia algo diferente acontecendo com a criança.

Na categoria Tratamento,foram enfocadasas crenças sobre os profissionais e serviços ligados ao atendimento ao filho. No caso dos profissionais, o Senso de Amparo no tratamento do filho foi relacionado à sua habilidade ao lidar com a família e saber trabalhar com os pais as expectativas sobre o autismo e as potencialidades do filho (p. ex., "não tem cura, mas tem tratamento" [P2]). O Senso de Amparo também foi expresso pela capacidade de saber "escutar e entender"[P1] a família e de trocar informações com eles, bem como pela habilidade para lidar especificamente com crianças com autismo, gostar de crianças e capacidade de trabalho em equipe: a possibilidade de os "profissionais trabalharem
conjuntamente"[P4]. Por outro lado, o Senso de Desamparo em relação aos profissionais, no tratamento das alterações relativas ao autismo no filho, foi relacionado à existência de poucos profissionais habilitados para o tratamento de crianças com autismo e à má qualidade da comunicação destes com as famílias. Nesse sentido, o Senso de Amparo no tratamento do filho foi expresso principalmente pela existência de um profissional de referência que facilitasse a comunicação entre os diversos profissionais envolvidos e destes com os pais, além da existência de centros integrados de atendimento às crianças e seus familiares:

As pessoas chegam num determinado estágio de conhecimento a respeito do autismo depois de muito esforço... correndo atrás...

falta algum lugar, assim tipo um centro integrado, sabe? Onde tu pudesse chegar lá,... atendessem a criança, atendessem os pais, tivesse orientação, sabe? [P5]

A última categoria temática sobre Autismo foram crenças sobre o Impacto Familiar do Diagnóstico: as reações emocionais, a relação dos pais e deles com a família e as relações sociais. Quanto às reações emocionais, predominou um Senso de Desamparo dos pais pelos medos sobre o desenvolvimento do filho (p. ex., crises epiléticas, deficiência mental, agressividade); medos acerca do futuro (p. ex., filho sofrer preconceito e não ter quem o cuide no futuro) bem como reações de negação ativa do diagnóstico e sentimentos de desânimo: "eu neguei, assim, eu achei que não, que depois ele ia, à medida que ele ia crescendo que ele não ia ser autista... não acreditava"[M5]. Em nenhum dos participantes, esse momento de impacto inicial do diagnóstico foi relatado diferente de uma vivência profundamente abaladora, o que evidencia a importância de desenvolvimento de habilidades para trabalhar com os pais nesse período.

O Senso de Amparo na relação do casal de pais frente ao Impacto Familiar do Diagnóstico foi representado pela existência de conversas e entendimento do casal. Já oSenso de Desamparo foi expresso, por exemplo, como diminuição da empatia do casal no período crítico e busca de culpados entre eles. De fato, para Lamanna e Riedman (2009), a necessidade de culpar alguém pelos problemas dificulta que possam encarar a adversidade como um desafio. Já o desenvolvimento de uma comunicação mais aberta e apoiadora é um facilitador ao lidar com a crise, tal como descrito pelos participantes desta pesquisa. O impacto do diagnóstico foi relacionado a um Senso de Desamparo dos pais quando houve desinvestimento no filho com autismo. Esse desinvestimento, por vezes, foi relacionado a um afastamento parental pela crença de rejeição por parte do filho. A dificuldade dessas crianças com a interação social recíproca e a comunicação pode estimular crenças distorcidas de rejeição que acabem por dificultar o investimento no filho e em si como pai ou mãe: "no começo ele era pequenininho e eu chamava ele e ele nem dava bola... pedia pra vir no colo ele não vinha. Até um dia eu disse pra ela, eu nem vou procurar ele, ele não me procura"'[P2].

O Senso de Amparo no impacto familiar do diagnóstico também foi expresso pelas relações sociais, por meio da ajuda espontânea de amigos e dos pais de outras crianças com autismo, que auxiliavam com a vivência deles e eram fontes de identificação. O Senso de Desamparo nas relações sociais foi retratado pelo preconceito da família, dos amigos 
e pelo isolamento social. Esse processo de exclusão social, na opinião de Serra (2010), é muito frequente e independe, muitas vezes, da situação socioeconômica da família. Nos casais participantes, o afastamento foi visto como recíproco - pessoas se afastaram da família e a família se afastou das pessoas. Por vezes, o afastamento dos pais visava evitar impor a convivência dos demais com o filho, até porque, como referem Lamanna e Riedman (2009), as famílias ao se sentirem estigmatizadas, tendem a se afastar de recursos.

Quando o tema abordado nas entrevistas foi o Filho, as principais categorias que emergiram foram Características do Filho e Expectativas Futuras em relação a este, sendo que os relatos envolviam crenças nas potencialidades ou nos comprometimentos dele. Quanto às Características do Filho, o Senso de Amparo estava relacionado a crenças nas potencialidades do filho. A ênfase nas potencialidades afetivas foi acompanhada da visão do filho como carinhoso, afetuoso e que pode ser ainda melhor entendido pelos demais, podendo entender mais. Também foi expressa pelo otimismo dos pais quanto ao desenvolvimento da criança, curiosidade quanto ao seu potencial, curiosidade frente ao autismo, valorização dos ganhos do filho, crenças relacionadas à capacidade de esperança. A ênfase nas potencialidades cognitivas se referiu a crenças que ele se desenvolvia, mesmo que de forma diferente das outras crianças. Outras capacidades valorizadas foram a percepção de que filho não era discriminado pelas outras crianças, que era capaz de evoluir, de ter certa independência e de ser uma criança cativante e afetuosa.

O Senso de Desamparo foi relacionado à ênfase nos comprometimentos ao se referir às características do filho, como, por exemplo, queixas de aspectos comportamentais (p. ex., filho descrito como teimoso, cansativo, medroso, inadequado, sem aceitação de convivência social etc.), a aspectos emocionais (dependência excessiva e falta de tolerância à frustração), a problemas na comunicação (dificuldade de se expressar pela palavra). Pesquisas sobre o desenvolvimento das crianças com autismo e sobre a identificação desses sinais pelos pais indicam que diversas crianças com TEA apresentam atraso cognitivo e da linguagem, bem como uma dificuldade de autonomia em relação a rotinas nas atividades da vida diária (AVD), principalmente em casos mais severos e que os pais, muitas vezes, percebem precocemente, em torno de 15 meses, indicativos desses comprometimentos através de dificuldades na socialização e, posteriormente, atraso da linguagem (Zanon, Backes, \& Bosa, 2014; Jasmin et al., 2009).

$\mathrm{Na}$ categoria Expectativas Futuras em Relação ao Filho, O Senso de Amparo foi relacionado a crenças de que filho poderá ter certa independência, desenvolver linguagem de forma que possa ser ainda melhor entendido, frequentar escola regular no futuro e aprender rotinas que facilitem seu desenvolvimento e capacidade de relacionamento. Algumas dessas expectativas aparecem, por exemplo, reunidas no relato a seguir: "a gente ainda espera que o João fale e que falando ele aprenda mais as rotinas, assim, do dia a dia, e que ele possa, se ele falar, que ele possa frequentar uma escola regular'[M5]. Já o medo de que o filho precise de cuidados contínuos gera um Senso de Desamparo nos casais: "todos dizem sempre que a gente não deve pensar nisso, mas a gente tem medo do futuro ... Ele vai durar muito ainda e eu não... e aí quem é que vai cuidar dele? Ele vai viver sozinho? Aonde? Como? Com quem? Não, né'[M5]. Algumas poucas pesquisas (Hendricks, 2010) são dirigidas à elaboração de estratégias para a família e para a pessoa com autismo para a vida adulta. Os pais tendem a se deparar frequentemente com esses receios sobre o futuro e, de fato, como ressaltado nas pesquisas de Bruder, Kerins, Mazzarella, Sims e Stein (2012) e Marques e Dixe (2011), ainda há muita escassez de serviços preparados para orientação dos adultos com autismo e para auxiliarna transição para uma vida adolescente ou adulta. Exemplos dessas dificuldades são a falta de informação sobre adultos com autismo e sobre os serviços futuros de que o filho possa vir a beneficiar-se, bem como a falta de treinamento dos profissionais nesse sentido, especialmente sobre cuidados com a saúde (Hendricks, 2010).

No tema Casal, foram identificadas as categorias de Vivência daCoparentalidade, Vivência daConjugalidade, Visão de Família e Recursos Sociaise Econômicos. $\mathrm{Na}$ categoria que envolve a Vivência de Coparentalidade na relação do casal, o Senso de Amparo foi expresso em crenças relativas à esperança dos parceiros, justiça na divisão de tarefas e na responsabilidade e boa comunicação do casal nos aspectos relativos ao filho. A esperança na relação coparental foi representada através de (a) relatos da valorização ou respeito às diferenças no cuidado com filhos, (b) crença na capacidade de aprendizado com parceiro(a) e de que vale a pena pedir ajuda a este(a), e (c) crença na capacidade de re-construir o "ser pais" e a crença de que ter um filho com autismo faz sentido como possibilidade de desenvolvimento e não os vitimiza, ou seja, a condição de atribuir um sentido a essa vivência, aspecto importante na promoção da resiliência parental e familiar (Walsh, 2012).

O sentido encontrado pelos casais na vivência de ter um filho com diagnóstico de TEA foi a possibilidade de revisão de valores e prioridades na vida: "uma maior valorização da vida" [M4], desenvolvimento da capacidade de empatia e crença de que esse filho veio para crescimento deles:"o João na verdade é uma criança, uma criatura que veio pra nós pra nos trazer muita informação"[M1]. O Senso de Amparo na relação coparental também foi expresso na busca de sentido para o autismo no plano espiritual/religioso, por exemplo, na crença que "Deus é um guia familiar" [M5] e que o autismo "é parte de um plano espiritual" [M5]. Isso proporcionava um sentimento de esperança nos casais. Por outro lado, o Senso de Desamparo na coparentalidade relacionou-se à busca incessante de culpados, ao sentimento de condenação e de que um filho com autismo é um "fardo" para eles [P5; P2].

Quanto à divisão de tarefas e responsabilidades relacionadas à criança, o Senso de Amparo foi relacionado a crenças de potencialidades dos casais, como, por exemplo, na possiblidade de cada um assumir aquilo que sente que tem mais facilidade de desempenhar, de combinações do casal sentidas como justas por ambos e na empatia entre os parceiros: conhecer "os sinais do outro" e saber "a hora de assumircuidado com o filho para aliviar" o(a) parceiro(a) [M1].

O Senso de Amparo na coparentalidade também foi enfatizado por meio do reconhecimento da união do casal e da flexibilidade na reação deles frente a/o parceira/o. No 
primeiro aspecto, envolveu, por exemplo, companheirismo, solidariedade, apoio (p. ex., incentivo ao desenvolvimento do outro). Já a flexibilidade na relação coparental foi enfatizada através da capacidade para mudanças adaptativas frente ao autismo (p. ex., na revisão do que seja o crescimento e evolução do filho), bem como na crença na capacidade de reconstrução da vida familiar e quando as diferenças no casal são vistas uma potencialidade de recursos.

O Senso de Desamparo foi relacionado à divisão de tarefas e responsabilidades relacionadas à criança quando há sobrecarga de um dos parceiros, falta de negociação e sentimentos de injustiça na divisão (p. ex., "parecia que tudo era só eu, que o filho era somente meu"[M5]). O Senso de Desamparo foi relacionado a comprometimentos da coesão na relação coparental, tais como percepção de dificuldades com proximidade (p. ex., sentimentos de solidão no casal), com a solidariedade (p. ex., parceiro intrusivo) e a pouco apoio mútuo sentido. Quanto à flexibilidade, o Senso de Desamparo foi retratado por meio de uma ênfase em dificuldades frente a mudanças necessárias e da baixa tolerância frente as diferenças entre os parceiros, bem como de queixas de falta de criatividade do casal para resolver situações críticas e gerar alternativas. O Senso de Amparo na coparentalidade também foi relacionado à qualidade da comunicação entre os pais. Esses indicativos foram a crença na capacidade de expressão clara de ideias nos momentos críticos (p. ex., nas crises, cobranças, busca de entendimento), na expressão de sentimentos (p. ex., mágoa, tristeza, (in)satisfação, expectativas, irritação, felicidade) e no respeito à diferença de opiniões. Já o Senso de Desamparo na comunicação coparental foi marcado por ênfase na busca de culpados pelos problemas da relação, à hostilidade na comunicação, sentimento de não ser entendido pelo parceiro, baixa colaboração na resolução de problemas e, ainda, pouca capacidade ou interesse de conciliação. A capacidade de resolução de problemas é uma capacidade desenvolvida nas relações e um fator considerado essencial para que a resiliência ocorra. Na concepção de Marturano, Linhares e Loureiro (2004), as habilidades requeridas para a resolução de problemas incluem identificação dos sentimentos - tantos seus como dos outros - e consideração do ponto de vista destes, bem como refletir sobre a existência de diferentes soluções para o mesmo objetivo e sobre as consequências dessas soluções, tanto em ações quanto em sentimentos, para então decidir qual sua atitude.

$\mathrm{Na}$ categoria da Conjugalidade,o Senso de Amparo foi relacionado a relatos que enfatizavam a esperança dos parceiros da vida conjugal ser reinvestida ou resgatada futuramente, bem como pela presença de desejo de romantismo e valorização do(a) parceiro(a) como marido/ esposa. O Senso de Amparo também foi despertado pela crença na presença de proximidade e apoio, aspectos relacionados à coesão dos casais. Esses aspectos foram expressos por meio de relatos do desejo de estarem juntos e da busca de aproximação entre eles para realizarem mudanças em suas vidas.

O Senso de Desamparo na vivência da conjugalidade foi expresso, por exemplo, pela falta de esperança na relação afetiva e íntima como casal ou inexistência de romantismo. Nesse sentido, alguns casais manifestaram a crença de que a vivência com autismo impede ou acaba com o romantismo e companheirismo e, assim, descreveram sua relação naquele momento por meio de comprometimentos: "não rola naturalmente, entendeu? Tu tem que ter um esforço maior... É, é dificil. Nesse sentido, acho que por isso que os casais, muitos casais se separam quando têm um filho assim, porque eles querem ficá na deles, entende? Tu não qué mais a outra pessoa do teu lado, quando tu pode, tu qué ta sozinho. É mais ou menos isso, por isso que fica difícil o relacionamento"'[M5]. As dificuldades na resolução de conflitos conjugais foram relacionadas a um Senso de Desamparo principalmente quando o filho com autismo ou exclusivamente um dos parceiros era considerado o problema do casal. Isso porque essa crença dificultava que assumissem seus conflitos.

Quanto aos Recursos Sociais e Econômicos do Casal, o Senso de Amparo do casal ficou evidenciado pela expectativa de equilíbrio entre trabalho e exigências familiares. Equilibrar tais custos requer: organização familiar, criatividade (p. ex., busca de novas alternativas) e mobilização de recursos, isso porque "o custo de ter uma criança com autismo é alto" [C5].

A existência de uma rede de apoio também foi relacionada ao Senso de Amparo do casal, principalmente na crença em sua capacidade de buscar e mobilizar uma rede. A rede de apoio nesse contexto foi considerada pelos pais como, principalmente, a família extensiva, pais de outras crianças com autismo e a rede de apoio formal (profissionais da saúde, educação, escola, etc.). Nesse sentido, a escola, por exemplo, foi considerada uma grande fonte de apoio, pois, de acordo com os casais, são pessoas que "conhecem bem" o filho. Já o contato com outros pais que têm filhos em situação semelhante pode trazer auxílio com suas experiências, principalmente na forma de lidar com a criança com autismo e em relação à escolha de profissionais. Além da rede de apoio, a mobilização também envolveu o processo de busca de informação e de conhecimento do que se passava com o filho e conhecimento sobre autismo, como, por exemplo, leituras relacionadas ao tema, participação em grupos, palestras e busca de direitos legais.

A partir dos relatos dos pais, compreende-se que a crença na existência de alternativas é um facilitador para visualizar e acessar esses recursos, pensar em formas de buscá-los e usufruir desses recursos, ou seja, tirar satisfação das capacidades do casal e da família, o empoderamento dos pais. Em outras palavras, de acordo com o relato dos pais, o processo de resiliência se põe em marcha na busca ou geração de recursos econômicos e sociais por meio da esperança e atribuição de sentido, criatividade e perseverança, capacidade de comunicação e de organização para a ação, bem como senso de merecimento.

De forma geral, apresentou-se um panorama de sua vivência no contexto do autismo desde o início do que consideraram o processo diagnóstico do filho até o momento da entrevista, decorridos alguns anos entre um momento e outro. Essa vivência mostrou-se profundamente abaladora em um momento inicial para todos os casais. A partir daí, diferentes rumos se estabeleceram, ressaltando as diferenças e semelhanças na elaboração do diagnóstico pelos casais, desde os que se reestruturaram de forma que consideram muito satisfatória (alguns com ampliação de recursos em vários 
níveis) até os que relataram que sua vida estava entregue ao autismo, sentindo-se exaustos, com poucos recursos e, principalmente, ainda sem sentido para essa vivência. A falta de sentido para essa vivência mostrou-se um fator forte de desamparo dos pais, como retratado no relato de João: " $A$ minha a maior expectativa agora é encontrar um sentido na minha vida pra atual situação, eu não tenho, sabe? ...Porque é tudo muito triste, assim, sabe? eu me sinto inadequado, me sinto... como se fosse um esforço,... tem que ter um sentido pra isso, mas eu não tenho um sentido pra isso"[P5].

No período da comunicação diagnóstica, os pais, em geral, sentiram-se invadidos por informações, demandas de exames, avaliações e intervenções, concomitante aos seus sentimentos de medo e tristeza. Além disso, nesse período inicial, eles se sentiram esvaziados de informações e de um "saber" acerca da sua família, pois parte dos projetos existentes até aquele momento para a família e das expectativas em relação ao filho teriam que ser revistas. De fato, quanto ao aspecto do empoderamento (Singh, 1995), inicialmente os pais ainda não são protagonistas da sua vivência, pois não têm um senso de controle satisfatório sobre aquelas circunstâncias. Isso tendeu a mudar posteriormente quando encontraram formas de lidar que contemplassem o seu jeito, o jeito do filho e as indicações dos profissionais. $\mathrm{O}$ desenvolvimento do empoderamento enquanto forma de protagonismo, de fato, mostrou-se como parte importante do processo de resiliência.

$\mathrm{O}$ sentido atribuído às vivências, a esperança e a perseverança (Walsh, 2012) mostraram-se fatores decisivos na resiliência parental, até porque foram fatores que facilitaram a mobilização do casal para as mudanças (ou não). De forma geral,as vivências, a esperança e a perseverançasão baseadas nas crenças de cada um, em um contexto de vida facilitador ou não, e no resultado de seu percurso, no qual as respostas podem reforçar antigas crenças (facilitadoras ou não) e mesmo gerar novas possibilidades.

Nesse sentido o Senso de Amparo dos casais foi enfatizado pela crença na possibilidade de sua evolução como pais e na evolução do filho. A possibilidade de significação dessa vivência, de fato, foi permeada pela esperança no potencial de desenvolvimento do filho e pela capacidade de não se aprisionar frente a poucas respostas sobre o que seja o autismo. Essa vivência, facilitadora da elaboração parental do diagnóstico, pode ser tão bem retratada na narrativa de um pai: "A minha a maior expectativa agora é... encontrar um sentido na minha vida pra atual situação, eu não tenho, sabe?... Porque é tudo muito triste, assim, sabe? eu me sinto inadequado, me sinto... como se fosse um esforço... tem que ter um sentido pra isso, mas eu não tenho um sentido pra isso"'[P5].

Para Bayat e Schuntermann (2009), em um primeiro momento, os pais podem buscar um sentido para o autismo e o que isso possa representar para o filho e para a família. Em um segundo nível, eles podem (re)construir um significado de sua identidade como família e decidir sobre as demandas e papeis de cada membro no atendimento à criança com autismo. Posteriormente ainda podem (re)construir um significado sobre sua visão de mundo. Auxiliar os pais na construção de significados globais e específicos sobre ter uma criança com autismo pode auxiliá-los a melhor lidar com essa situação, a promover resiliência e a melhorar o funcionamento familiar. De fato, isso sugere que a formação das crenças, nesse contexto do autismo, atuou como um processo dinâmico na elaboração do diagnóstico para esses casais. Semelhantes resultados sobre a influência das crenças na reação ao diagnóstico foram obtidos nas pesquisas de Dardennes et al. (2011), Harrington et al. (2006), Selkirk et al. (2009) e Sperry e Shafranske (2005). O desenvolvimento da resiliência foi representado pelo sentimento de crescer, colocar foco no cuidado do filho com autismo e, com o tempo, adquirir novas formas de cuidar da família e lidar com outros desafios que surjam nesse contexto.

\section{Considerações Finais}

Os indicadores de resiliência foram classificados a partir do que, de acordo com o relato dos pais, gerou-lhes um Senso de Amparo e, por outro lado, Senso de Desamparo, bem como a ênfase em comprometimentos ou em potencialidades. Esse tipo de análise se revelou útil para a identificação e compreensão dos componentes da resiliência que, por sua vez, fazem parte do que se considerou como elaboração do diagnóstico de autismo pelos pais. Nesse sentido, com base nos pressupostos teóricos aqui utilizados, pode-se concluir que "elaborar" o diagnóstico de um filho significa desenvolver processos de resiliência que permitam não apenas o desenvolvimento do filho, mas da família.

Ainda que a principal limitação deste estudo tenha sido a de se elaborar um sistema de categorias com base em entrevistas já transcritas, pertencentes a um banco de dados, o produto final parece ter suplantado essa eventual restrição. A matriz categórica gerada mostrou-se útil no mapeamentodos indicadores de resiliência mesmo que os tópicos das entrevistas originais não tenham sido desenvolvidos com esse propósito. Isso foi possível porque os temas investigados no estudo original eram correlatos ao conceito de resiliência. $\mathrm{O}$ presente estudo tem potencial para gerar outros, replicando-se essa matriz em, por exemplo, casais cujo filho tenha acabado de ser diagnosticado com TEA. Finalmente, acredita-se que esses resultados tenham implicações imediatas para a formação de profissionais que trabalham com famílias nesse contexto, assim como para orientação de programas de intervenção voltados ao impacto inicial do diagnóstico de autismo na família.

\section{Referências}

Amar, J., Gonzáles, M., \& Utria, L. (2013). Nuevo abordaje de la salud considerando la resiliência. Salud, Barranquilla, 29(1), 124-133.

American Psychiatric Association. (2013). Manual Diagnóstico e Estatístico de Transtornos Mentais (DSM-V). Porto Alegre: Artmed.

Barnhill, G., Polloway, E., \& Sumutka, B. (2011). A survey of personnel preparation practices in autism spectrum disorders. Focus on Autism and other Developmental Disabilities, 26(2), 75-86.doi:10.1177/1088357610378292. 
Bayat, M.,\& Schuntermann, P. (2009). Enhancing resilience in families of children with autism spectrum disorders. In D. Becvar (Org.), Handbook of Family Resilience (pp. 409-425). New York: Springer.

Biasoli-Alves, Z. M. M. (2000). Continuidades e rupturas no papel da mulher brasileira no século XX. Psicologia Teoria e Pesquisa,16(3), 233-9.doi:0.1590/S010237722000000300006.

Bruder, M., Kerins, G., Mazzarella, C., Sims J., \& Stein, N. (2012). Brief report: The medical care of adults with autism spectrum disorders: Identifying the needs. Journal of Autism and Other Developmental Disorders, 42(11), 2498-2504.doi:10.1007/ s10803-012-1496-x.

Connolly, C. M. (2006). A feminist perspective of resilience in lesbian couples. Journal of Feminist Family Therapy, 18(1/2), 137-162.doi:10.1300/J086v18n01-06.

Dardennes, R., Al Anbar, N., Prado-Netto, P., Kaye, K., Contejean, Y., \& Al Anbar, N. (2011). Treating the cause of illness rather than the symptoms: Parental causal beliefs and treatment choices in autism spectrum disorder. Developmental Disabilities, 32(3), 1137-1146. doi:10.1016/j.ridd.2011.01.010.

Fleischmann, A. (2004). Narratives published on the internet by parents of children with autism: What do they reveal and why is it important? Focus on Autism and Other Developmental Disabilities, 19(1), 35-43. doi:10.1177/1088357604019001 0501.

Gardner, J., \& Harmon, T. (2002); Exploring resilience from a parent's perspective: A qualitative study of six resilient mothers of children with an intellectual disability. Australian Social Work, 55(1), 60-68.doi: 10.1080/03124070208411672.

Harrington, J. Patrick, P., Edwards, K.,\& Brand, D. (2006). Parental beliefs about autism: Implications for the treating physician. Autism, 10(5), 452-462.doi: 10.1177/1362361306066609.

Hartling, H. (2008). Strengthening resilience in a risky world: It's all about relationships. Women \& Therapy, 31(2), 51-70. doi:10.1080/02703140802145870

Heidgerken, A., Geffken, G., Modi, A., \& Frakey, L. (2005). A survey of autism knowledge in a health care setting. Journal of Autism and Developmental Disorders, 35(3), 323-330.doi: 10.1007/s10803-005-3298-x.

Hendricks, D. (2010). Employment and adults with autism spectrum disorders: Challenges and strategies for success. Journal of Vocational Rehabilitation, 32(2), 125-134.doi:10.3233/JVR2010-0502.

Herbert, E., \& Koulouglioti, C. (2010). Parental beliefs about cause and course of their child's autism and outcomes of their beliefs: A review of the literature. Comprehensive Pediatric Nursing, 33(3), 149-163.doi:10.3109/01460862.2010.498331.

Hutton, A. M., \& Caron, S. L. (2005). Experiences of families with children with autism in rural New England. Focus on Autism and Other Developmental Disabilities, 20(3), 180-189.doi:1 0.1177/10883576050200030601.

Jasmin, E., Couture, M., McKinley, P., Reid, G., Fombonne, E., \& Gisel, E. (2009). Sensori-motor and daily living skills of preschool children with autism spectrum disorders. Journal of Autism and Developmental Disorders, 39(2), 231-241. doi:10.1007/s10803-008-0617-z.

Koller, S., Dell'Aglio, D.,\& Yunes, M. A. (2006). Resiliência e psicologia positiva: Interfaces do risco à proteção. São Paulo: Casa do Psicólogo.
Lamanna, M., \& Riedmann, A. (2009). Marriages and families: Making choices in a diverse society. Belmont, CA: Thomson.

López, M. J. (2009). Una mirada integradora de la resiliencia parental: Desde el contexto hasta la mente de las madres y los padres en riesgo psicosocial. Psicologia da Educação, $28,51-71$.

Marques, M., \& Dixe, M. A. (2011). Crianças e jovens autistas: Impacto na dinâmica familiar e pessoal de seus pais. Revista de Psiquiatria Clínica, 38(2), 66-70. doi: 10.1590/S010160832011000200005.

Marturano, E., Linhares, M. B., \& Loureiro, S. (2004). Vulnerabilidade e proteção: Indicadores na trajetória do desenvolvimento do escolar. São Paulo: Casa do Psicólogo.

Meimes, M. (2014). A interação mãe-criança e autismo contribuição dos fatores psicossociais (Dissertação de mestrado não publicada). Programa de Pós-Graduação em Psicologia, Universidade Federal do Rio Grande do Sul, Porto Alegre.

Melillo, A.,\& Ojeda, E. (2005). Resiliência: Descobrindo as próprias fortalezas. Porto Alegre: Artmed.

Milshtein, S., Yirmiya, N., Oppenheim, D., Koren-Karie, N., \& Levi, S. (2010). Resolution of the diagnosis among parents of children with autism spectrum disorders: Associations with child and parents characteristics. Journal of Autism and Developmental Disorders, 40, 89-99. doi:10.1007/s10803009-0837-x.

Minayo, M. C. (2006). O desafio do conhecimento: Pesquisa qualitativa em saúde. São Paulo: Hucitec-Abrasco.

Muller, C. (2012). Conhecimento dos estudantes de medicina acerca do autismo em uma universidade do Rio Grande do Sul (Dissertação de mestrado não publicada). Faculdade de Medicina. Programa de Pós-graduação em Saúde da Criança e do Adolescente, Universidade Federal do Rio Grande do Sul, Porto Alegre, RS.

Núcleo Integrado de Estudos e Pesquisa em Transtornos do Desenvolvimento. (2004). Roteiro para entrevista conjunta sobre a coparentalidade. (Unpublished instrument). Instituto de Psicologia, Universidade Federal do Rio Grande do Sul, Porto Alegre, Brasil.

Osborne L. A., \& Reed P. (2008). Parents' perceptions of communication with professionals during the diagnosis of autism. Autism, 12(3), 309-324. doi:10.1177/1362361307089517.

Patterson, J (2002). Understanding family resilience. Journal of Clinical Psychology, 58(3), 233-246.doi:10.1002/jclp.10019.

Paula Júnior, W., \& Zanini, D. (2011). Estratégias de coping de pacientes oncológicos em tratamento radioterápico. Psicologia: Teoria e Pesquisa, 27(4), 491-497.doi:

10.1590/S0102-37722011000400013.

Pinker S. (2004). Tabula rasa: A negação contemporânea da natureza humana. São Paulo.

Poletto, M. (2008). Resiliência: Nova perspectiva sobre as potencialidades humanas. Polêmica Revista Eletrônica, 7(3), 76-81.

Reppold, C., Mayer, J., Almeida, L., \& Hutz, C. (2012). Avaliação da Resiliência: Controvérsia em torno do uso das escalas. Psicologia: Reflexão e Crítica, 25(2), 248-255.doi: 18822935004.

Rooke, M., \& Pereira-Silva, N. (2012). Resiliência familiar e desenvolvimento humano: Análise da produção científica. Psicologia em Pesquisa/ UFJF, 6(2), 179-186.doi:

10.5327/Z1982-12472012000200011. 
Ruini, C., \& Fava, G. (2013). The polarities of psychological well being and their response to treatment. Terapia Psicológica, 31(1), 49-57. doi:78525710005.

Scheuermann, B., Webber, J., Boutot, E., \& Goodwin, M. (2003). Problems with personnel preparation in autism spectrum disorders. Focus on Autism and Other Developmental Disabilities, 18, 197-206.doi:10.1177/10883576030180030 801.

Schmidt, C.,\& Bosa, C. (2007). Estresse e auto-eficácia em mães de pessoas com autismo. Arquivos Brasileiros de Psicologia, 59(2), 179-191.doi:229017529008.

Selkirk, C., Veach, P. M., Lian, F., Schimmenti, L., \& LeRoy, B. (2009). Parents' perceptions of autism spectrum disorder etiology and recurrence risk and effects of their perceptions on family planning: Recommendations for genetic counselors. Journal of Genetic Counseling, 18(5), 507-519.

Semensato, M., Schmidt, C., \& Bosa, C. (2010). Grupo de familiares de pessoas com autismo: Relatos de experiências parentais. Aletheia, 32, 183-194.doi:115020838015.

Semensato, M., \& Bosa, C. (2014). Apego em casais com um filho com autismo. Fractal, Revista de Psicologia, 26(2), 379-400. doi: 10.1590/1984-0292/839.

Serra, D. (2010). Autismo, família e inclusão. Polêm!ca, 9(1), 40-56.
Sifuentes, M., \& Bosa, C. (2010). Criando pré-escolares com autismo: Características e desafios da coparentalidade. Psicologia em Estudo, 15(3), 477-485.

Singh, N. (1995). In search of unity: Some thoughts on familyprofessional relationships in service delivery systems. Journal of Child and Family Studies, 4, 3-18. doi:10.1007/ BF02233951.

Sperry, L. E., \& Shafranske, E. P. (2005). Spiritually oriented psychotherapy. Washington, US: American Psychological Association.

Walsh, C., \& O'Leary, D. (2013). A comparative study of the marital relationship between parents with children with autism and those with children without children with autismo. Good Autism Practice, 14(1), 28-33.

Walsh, F. (2012). Family resilience: Strengths forged through adversity. In Normal family processes (pp. 339-427). New York: Guilford Press.

Yunes, M., \& Juliano, M. (2010). A bioecologia do desenvolvimento humano e suas interfaces com educação ambiental. Cadernos de Educação PPGE/UFPel, 37, 347 - 379.

Zanon, R., Backes, B., \& Bosa, C. (2014). Identificação dos primeiros sintomas do autismo pelos pais. Psicologia: Teoria e Pesquisa, 30(1), 25-33. doi: 10.1590/S0102-37722014000100004 